\title{
LAS MUJERES INDÍGENAS Y SU INCURSIÓN LABORAL EN LA COLONIA: \\ LOS CONTRATOS DE TRABAJO EN CUSCO (1600-1650)
}

\author{
ÑAUPAQ COLONIA NISQA PACHAPI KIKIN LLAQTAYUQ \\ WARMIKUNA LLANK AYMAN HAYKUSQANKU \\ LLANK'AYKUNA CONTRATUYUQ KASQA CUSCO LLAKTAPI
} (1600-1650)

\section{INDIGENOUS WOMEN AND THEIR LABOR INCURSION IN THE COLONY: EMPLOYMENT CONTRACTS IN CUSCO (1600-1650)}

\author{
Luz Amparo Ramos Ayala(1) \\ Universidad Nacional de San Antonio Abad del Cusco \\ Universidad del País Vasco
}

\begin{abstract}
Resumen: Este artículo muestra, a través de los "conciertos" (contratos de trabajo) tramitados ante funcionarios oficiales y notarios, las formas de la incursión laboral de las mujeres indígenas en el Cusco colonial (siglo XVII), en el marco de la consolidación del modelo económico colonial, del quiebre y remoción de las practicas socioeconómicas tawantinsuyanas y la instauración de la nueva economía colonial monetaria (en minería, comercio, agricultura, etc.). Las mujeres indígenas se incorporan activamente al mercado laboral como ayuda a sus familias, pero también como una forma de resistencia activa. Incursionan en la nueva economía de dos formas: subordinada (amas de leche, empleadas domésticas, cocineras, lavanderas y chicheras), sujetas a un contrato de trabajo con un salario específico, y no subordinada (panaderas, carniceras, costureras, etc.). Finalmente, se muestran los salarios percibidos por varones y mujeres Indígenas.
\end{abstract}

(1) Magister en políticas lingüísticas por la Universidad del País Vasco. Historiadora y especialista en conservación y restauración de bienes culturales por la Universidad Nacional de San Antonio Abad del Cusco (Perú) (e-mail: luz.ramos.ayala@gmail.com) 
Palabras clave: género, mujer indígena, incursión laboral, mercado laboral, contrato de trabajo.

Ch'uyanchakuy: Kay qilqaypin qhawachikun, imaynan kamachiykunaq "Ilank’aykuna contratuyuq" haykuranku Ilank’aypaq. Imaykunamantaraq kikin Ilaqtayuq warmikunapaq Ilankàq kananpaq Qusqu Ilaktapi chay colonia nisqa pachapi, chaykunapis karan sumaq allin kananpaq, chay jina económico colonial nisqa sutiyuq kanapaq, chinkachinapaq, p’ampanapaq, ñawpaq sumaq llank aykuna tawantnsuyupi kasqanta, chayta ruwaspaqa kallarikunanpaq huq musuq llank`ay qullqillapi kananpaq (mineriapi, comerciopi, agriculturapi, etc.). Warmikunaqa chay llank ayman haykunku viva viva hina, ayllunku yanapanankupaq, wakinpitaq ñaupaq kausay mana tukunanpaq. Kikin Ilaqtayuq warmikunaqa chay Ilank ayman haykunku iskay partimanta: i) pituchasqa hina (wawankuta leche kunanpaq, wasi uhukunapi llankaspa, wayk uspa, t’aqsaspa, aqha ruwaqkuna), contratasqa llank’anakunaman hina, huq chaninchayoq; ii) mana pituchasqa hina (tantata ruwaspa, aychata ranqhaspa, awaykunatas ruwaspa). Kikin Ilaqtayuq warmikuna masinwankuna contratukunata ruwaspa. Tukunapaq, qhawachikun kikin llaqtayuq warmikunaq, qharikunaq, chanincha chaskisqannkuta.

Yuyaysapa simikuna: Warmikunaq, kikin Ilaqtayuq warmi, Ilank'aykunaman qispiriy, Ilank'ana taripay, llank'anamanta chaninchaypas.

\begin{abstract}
This article shows, through the "concerts" (employment contracts) processed before official authorities), the forms of the labor incursion of Indigenous women in colonial Cusco within the framework of the consolidation of the colonial economic model, of the break and suppression of Tawantinsuyan socio-economic practices and the establishment of the new colonial monetary economy (in mining, commerce, agriculture, etc.). Women actively enter the labor market as a form of help to their families, but also as a form of active resistance. Indigenous women enter the new economy in two ways: subordinate, subject to an employment contract with a specific salary (ie, wet nurse, maids, cooks, laundresses and chicha makers) and non-subordinate (ie, bakers, butchers, seamstresses, etc.). Indigenous women (of the upper-class and lower-class) also sign service contracts with other Indigenous people. Finally, salaries received by Indigenous men and women are shown.
\end{abstract}

Keywords: Gender, Indigenous woman, labor incursion, labor market and employment contract. 


\section{La estructura social colonial}

Para tratar acerca de la estructura social colonial en el virreinato del Perú es necesario abordar a la población indígena con una estructura organizacional propia, que vivía y se desarrollaba en un medio ambiente. En este sentido, con la llegada de los peninsulares al territorio peruano en 1532, se quiebra abruptamente la unidad social andina, puesto que el proceso de colonización se caracterizó por dividir a nivel social, cultural, económico y político la estructura prexistente. El estado In $\mathrm{ka}^{(2)}$ estaba conformado e integrado unificadamente por diversas naciones o estados señoriales regionales (basado en un incesante intercambio económico). En términos demográficos la invasión española significó una catástrofe que se traduce en la perdida aproximada del $90 \%$ de la población indígena, se calcula que sobrevivieron aproximadamente 1.000 .000 de 12.000 .000 de habitantes, los cuales mueren debido a las epidemias, abortos, acciones militares, mala alimentación, abusos, guerras, y extrema explotación laboral.

A lo largo de la formación de la referida estructura social colonial se da una serie de reajustes. ${ }^{(3)}$ El Virrey Toledo (1570) divide en dos grupos a la población de la sociedad colonial, la república de indios y la de españoles. En la cúspide de la nueva sociedad peruana se ubicó una pequeña élite blanca que dominó a la inmensa mayoría de indígenas, a quienes se excluyó sistemáticamente dentro de su angosta concepción europeizada de nación. ${ }^{(4)}$ La nueva ubicación social de los vencidos (indígenas) dentro de la estructura social colonial, tenía que ser justificada con argumentos de diversa índole, básicamente adoctrinamiento, pero el tema racial divide claramente a dos repúblicas, por un lado, blancos - españoles y por el otro indios - vencidos. A este respecto, Flores Galindo (1993) refiere que durante el periodo independiente del Tawantinsuyo en el territorio andino solamente existían runas (u hombres), fue recién después con el proceso de invasión que surge la categoría de indio, con el propósito de homogenizar forzosamente a la población vencida y reducir sus diversas expresiones culturales. ${ }^{(5)}$ En esta nueva sociedad

(2) La sociedad andina había logrado la unidad económico-social y política sobre la base de la agricultura complementada con el pastoreo y la manufactura textil dando origen a comunidades étnicas campesinas autosuficientes cuyo acceso a la tierra y cuyo cultivo era regulado por el parentesco y por definidas pautas de cooperación, cuya distribución agraria se efectuaba teniendo en cuenta las diferencias climáticas y la distinta rotación de los cultivos y cuyo excedente revertía parcialmente a la comunidad por medio de la redistribución estatal de diverso tipo de servicios. López, S., Araníbar, C., Bonilla, H., \& Burga, M. (1982). De imperio a nacionalidades oprimidas: notas sobre el problema nacional indígena. Nueva historia general del Perú. pág. 234.

(3) Según Tord, la estratificación Social en el Virreinato Peruano conformó una sociedad jerarquizada. La estratificación de esta sociedad estuvo regimentada por tres principios sociales divisionales, a saber: el estamental. el de castas y el de clases sociales. Nicolini, J.T., \& García, C. L. (1984). Una reseña critica de la dominación en el Perú virreinal (segunda parte). Histórica, 8(2), Págs. 197, 198 y 200.

(4) Klarén, Peter F; Nación y sociedad en la historia del Perú; Instituto de Estudios Peruanos; Lima 2004. Pág. 16.

(5) Flores, A. (1993). Buscando un Inka, Consejo Nacional para la Cultura y las Artes, Ed. Grijalbo, México 1993. Pág. 264. 
colonial, el grueso de la población indígena sufrirá exclusión (discriminación étnica e ideológica), postergación y estigmatización debido a su origen.

Varias son las situaciones que llevan a un estado de apremiante precariedad económica a los indígenas, una de ellas, y quizá la más importante, es el despojo de los indígenas que se plasma en la composición de tierras que no fue más que la apropiación de las tierras a favor del Rey Felipe II. Las mejores tierras del Estado Inka, que otrora estaban dedicadas a las deidades andinas, pasan a manos de los españoles convirtiéndose en las primeras haciendas. Por otro lado, se implementa la institución de la encomienda a través de la cual se entregaba un grupo de indios al cuidado de un encomendero español, ${ }^{(6)}$ con fines de evangelización y protección, pero "se mantenía una ficción de intercambio: tierra a cambio de servicios. Pero en realidad se exigían mayores servicios sólo para que no se quitara al Ayllu la tierra que poseía desde tiempo inmemorial. El antiguo principio de la reciprocidad quedaba sustituido por el de la simple explotación"(7). De esta forma, los integrantes del Ayllu, pagaban tributo (especies, dinero, mita), a cambio de ocupar las tierras. Esta situación se hace insostenible para la población indígena, por lo que muchos de ellos deciden abandonar las tierras que desde siempre ocuparon perdiéndolas irremediablemente.

El Virrey Toledo instaura grandes y significativos cambios: la creación de las reducciones, la recaudación de tributos y la mita (mano de obra para las obras públicas, priorizando labor minera). Estas medidas terminan por remover los cimientos de las tradiciones prehispánicas. Los indígenas constituirían la base de la reciente e instaurada pirámide social, siendo ellos la principal fuerza de trabajo de las recientes ciudades (desempeñándose en el campo agrícola, minero, y de obras públicas).

Las estructuras andinas, a causa de la invasión española, sufrieron profundos e irreparables cambios. Las mujeres indígenas en la época prehispánica de ocupar cargos como jefes, damas principales, capullanas y cacicas pasaron a ser concubinas de las huestes hispanas. Según Rostworowski:

Las consecuencias a nivel de las clases sociales elevadas fue su casi total exterminio, sufriendo las mujeres de la élite el de tornarse mancebas de los españoles. En cambio, las mujeres de los ayllus basados en las unidades domésticas y la familia extendida, tuvieron más posibilidades de sobrevivir que las de las clases elevadas. Esta situación hace posible estudiar las clases campesinas

(6) De acuerdo a las investigaciones históricas, en 1586 cada encomendero tenía bajo su potestad, su dominio y a su disposición un promedio de 7,096 indios. Valderrama, A. Y. (1995). Las" reducciones", uno de los instrumentos del etnocidio. Revista complutense de historia de América, (21), Págs. 241-264.

(7) Carter, W. y Albó, X (1988). "La comunidad Aymara: un mini-estado en conflicto". En: ALBÓ Xavier. Raíces de América: el mundo aymara. Madrid: Alianza Editorial, Pág. 453. 
actuales, observar en ellas las posibles continuidades y/o rupturas con la situación anterior. ${ }^{(\mathbf{8})}$

Particularmente, la Ciudad del Cusco (y otras ciudades coloniales) acogió a las mujeres indígenas tanto de la elite como del común y les ofreció oportunidades económico-laborales dentro de la instaurada sociedad colonial.

\section{La Ciudad del Cusco (época colonial)}

La ciudad del Cusco fue cuna de una de las pocas civilizaciones autónomas que trascendieron en el tiempo y el espacio, por ende, posee un sitial preeminente en la historia de la humanidad. Al respecto, Contreras y Valverde (1982) la describen como la gran ciudad del Cuzco, mayor en el nombre que en la vecindad, fue corte y asiento real de los reyes indios y de los españoles, el motivo de discordia. Está fundada en un valle que tendrá dos leguas de longitud y de latitud, poco más o menos de media. ${ }^{(9)}$ Luego de la invasión española (1532) se da lugar a la fundación de la ciudad del Cusco en 1534.

Uno de los principales motores de la economía de la época colonial fue la mina de Potosí. Junto con ciudades como Lima, Cusco, Huancavelica y Huamanga, contribuyó a la instalación de haciendas y obrajes por doquier. La producción agropecuaria y textil se convirtió en la forma cómo los encomenderos podían acceder al sector minero generador de beneficio metálico. La producción colonial incursionaría en diversos tipos de producción artesanal/gremial tales como la talabartería, hojalatería, cerería, platería, ebanistería, albañilería, etc.

En tal caso, en la época colonial, el Cusco fue ciudad-escala y se le semeja al cordón umbilical que unía a Lima con la región minera del Alto Perú. Era pues uno de los mayores productores y abastecedores de la hoja de coca, cereales, textiles (tocuyos y cordobanes - sombreros de lana de vicuña), se abastecía para sí de tollo, congrio y corvinas saladas de Arica y otros puertos, pero, además, servía como paso obligado debido a su privilegiada ubicación de otros productos como vino y yerba mate con destino a la mina de Potosí y hacia otras grandes ciudades de la época (cf. Salas, 2009).

En estas condiciones, y dado que los españoles ya no podían disponer como antes de la fuerza de trabajo indígena, tuvieron que buscar otros mecanismos legales e ilegales para cubrir esta apremiante necesidad. Trabajadores fuera de la ley: ${ }^{(10)}$ a) Indios enganchados (por deudas), b) Trabajadores en dupla (indios o indias

(8) Rostworowski, M. (1988). La mujer en el Perú prehispánico. Lima: IEP. Documento de Trabajo Nro. 17. Serie Etnohistoria Nro. 1. Pág. 13.

(9) Contreras y Valverde, V. D. (1982). Relación de la ciudad del Cuzco. Relaciones geográficas, 2. pág. 3. (10) Noejovich Chernoff, H., Suárez, M., Glave, L. M., Salas, M., \& Salazar-Soler, C. (2009). Compendio de historia económica del Perú ll: Economía del período colonial temprano. Lima. Págs. 485 y 486. 
acompañantes o auxiliares de los niños y viejos señalados por las provisiones), c) Indios de alquiler o "fuera de la cuenta" (obligados por contrato a servir en el obraje), d) Mujeres en general (si bien estaban fuera del circuito formal del trabajo, ayudaban a sus esposos, hijos, padres y hermanos en todo lo que se ofrecía, dado que a los hombres se les había multiplicado el trabajo y ellas debían atender las labores propias del hogar y de la chacra: "Se ayudan los dichos tributarios de sus mujeres"), e) indios yanaconas (eran aquellos que llegaban a trabajar a los obrajes).

Con respecto a los trabajadores legales o dentro de la ley, fue cubierta por los indígenas varones y mujeres. En el caso de la ciudad del Cusco en la primera mitad del s. XVII, la legalidad de los diversos trabajos realizados por las mujeres indígenas quedaba plasmado en un contrato de trabajo (no necesariamente individual), denominado "concierto", el cual era redactado por un escribano público y contenía los datos generales de la empleada (nombres, apellidos, origen étnico y geográfico, nombre de su cacique, estado civil), los datos del empleador(a) (nombre, apellidos y condición social), la descripción del trabajo a realizar, el tiempo, el monto de la remuneración (monetario y no monetario) y finalmente la fecha del documento. La incursión laboral de la mujer indígena quedó registrada en estos documentos archivísticos, se desempeñaron como amas de leche, chicheras, empleadas domésticas, lavanderas, cocineras, panaderas, costureras y carniceras.

\section{Incursión laboral de la mujer indígena cusqueña en la colonia}

La inclusión laboral de la mujer indígena en la sociedad colonial, según Burket (1976), se debió principalmente a aspectos como el tributo personal al que fueron sometidas (antes de las ordenanzas del Virrey Toledo) y las obligaciones de trabajo, legales e ilegales estipuladas por los encomenderos. Legalmente, estos servicios se reducían a cocinar, limpiar, coser, y desempeñar otras labores domésticas. $^{(11)}$

Para el caso de la Ciudad del Cusco, la documentación archivística (16001650), arroja que el $100 \%$ de las mujeres indígenas eran denominadas como "yndias" y se dilucida una clara diferenciación de la condición social entre yndios, mestizos y españoles. El contrato de trabajo, denominado concierto ${ }^{(12)}(16 / 05 / 1640)$ refiere que, "parescieron dos yndios... dixeron llamarse pedro guaman y juana ssissa su muger naturales del pueblo de accha sujetos a don juan guallpatami su caçique

(11) Burkett, E. (1976). La mujer durante la conquista y la primera época colonial. Estudios Andinos, 5(1), 4-25.

(12) El enganche deriva en cierta forma del "concierto" colonial. Este era lo que ahora llamaríamos el contra. to de trabajo. A diferencia de la mita, que era un trabajo forzado (aunque remunerado), el concierto se presumía que era el resultado de un convenio libre; pero, en la práctica, la autoridad exigía que los indios se concertasen y colocaba la fuerza al servicio de quienes tenían interés en concertar indios. de Trazegnies Granda, F. (1991). Paradojas de la Modernización: El Contrato de Enganche. THEMIS: Revista de Derecho, (20), Pág. 13 
conciertan con juana peres mestiza En avitos de yndia questa press ${ }^{\text {te }}$ (presente)."(13) Un aspecto resaltante, es que la diferencia del origen étnico estaba circunscrita incluso a la vestimenta de una u otra clase social. Socialmente la mujer indígena se desenvolvió en dos esferas: dentro de la macro-composición social colonial (ocupó el penúltimo lugar) y dentro de la población indígena en general (la cuota de machismo colocó a la mayoría de mujeres indígenas en una posición subordinada e inferior).

Las indígenas del presente estudio refieren ser originarias (naturales) de las 8 parroquias que conformaron la Ciudad del Cusco. ${ }^{(14)}$ De la documentación archivística se desprende que escribanos de la época de estudio registraron a las indígenas procedentes de las parroquias siguientes: San Blas, Nuestra Señora de Belén, Hospital de Naturales, Santa Ana, Santiago, San Cristóbal, San Sebastián y San Jerónimo. Otro tanto de ellas aseveraron ser específicamente de la ciudad del Cusco.

El desenvolvimiento legal-laboral de la mujer indígena, dentro de la sociedad colonial cusqueña, estuvo sujeta a varios aspectos condicionantes, entre ellos, su estado civil, (casada, soltera o viuda). En el documento siguiente (1640) se aprecia que una mujer indígena (casada/conviviente) para poder concertar sus servicios como cocinera, requería de un escribano público (notario), un intérprete (quechua-castellano hablante), el permiso de su cónyuge, indicar a qué cacique estaba sujeta, la presencia y ayuda del juez de naturales:

"ante mí el escribano publico E testigos pareció una yndia que por interpretación de Joan gomez de leon ynterprete = dixo llamarse maria nives mujer de diego quispe y ser natural de la parroquia del hospital de los naturales subjeto a don diego francisco su casique con licencia del dicho su marido y con presencia y asistencia de don diego de los rrios y valer vezino y juez de naturales desta ciudad (16/01/1640)."15)

En el caso de las indígenas solteras, para la redacción del contrato de trabajo básicamente debían indicar sus datos generales y a qué cacique estaba sujeta:

"... Parecio un yndia ... dixo llamarse maria mollo chimbo soltera natural de la parroquia de san blas sujeta a don diego

(13) ARC, Notarios, Alonso Calvo. (1639-1640). Protocolo: 44, Registro Nro. 7. Folio: s/f.

(14) Navia señala que, en el mes de mayo de 1558 la Ciudad de Cuzco, fue dividida en cinco parroquias, Santa Ana (barrio de Karmenqa), San Cristóbal (actual barrio de Qolqampata), San Blas, (barrio de Toqocachi), San Sebastián (barrio de Qolqapampa), Santos Reyes/Belen (barrio Inka Ilamado Qayaocachi). En la época del Virrey Francisco de Toledo se fundaron otras tres parroquias, Hospital de los Naturales o de San Roque (San Pedro), Apóstol Santiago, San Jerónimo, (ubicada en el sector de Surama y SuksoAuqayIli). Esquivel y Navia, D. (1980). Noticias cronológicas de la gran ciudad del Cuzco. Ed. F. Denegri Luna, Fundación Wiesse, Lima. pág. 298.

(15) ARC, Notarios, Alonso Calvo. (1639-1640). Protocolo: 44, Registro Nro. 6. Folio: 23 (reverso). 
canatopa su cacique conserto con mariana de sierra questa presente $(12 / 04 / 1640),{ }^{\prime \prime(16)}$

En el caso de las mujeres indígenas viudas, además de sus datos generales, se debía señalar el nombre del marido difunto:

"... Parecio un yndia... dixo llamarse maria de chaves y ser natural del pueblo de mara en los yanaguaras viuda de santiago pusac conserto con alonso dias davila (03/07/1640)."(17)

En síntesis, se puede apreciar que muchas mujeres indígenas abandonaron sus tierras y se dirigieron a las grandes ciudades (Cusco, Lima, Huancavelica, etc.) donde incursionaron en el campo laboral a cambio de una retribución económica.

\section{Mano de obra femenina indígena subordinada}

La mayoría de mujeres indígenas en la ciudad del Cusco incursionaron en el campo laboral colonial de forma subordinada, puesto que eran contratadas por otros. Esta subordinación laboral estuvo condicionada por dos aspectos:

1. Las mujeres indígenas no podrían acceder a aprender todos los oficios artesanales, este privilegio era casi exclusivo de los varones indígenas:

CUADRO NRO. 1: OFICIOS DE LOS INDÍGENAS EN EL CUSCO COLONIAL (1600-1650)

\begin{tabular}{|c|l|c|c|c|}
\hline Nro. & \multicolumn{1}{|c|}{ Nombre } & Oficio & Origen & Fecha \\
\hline 1 & Ambrosio Quispe & Albañil & Parroquia Belén & $03 / 01 / 1640$ \\
\hline 2 & Pedro Paucar & Carpintero & Pueblo de Quiquijana & $12 / 09 / 1650$ \\
\hline 3 & Pascual Paucar Sinche & Zapatero & Parroquia de Santa Ana & $04 / 02 / 1640$ \\
\hline 4 & Jeronimo Callaconchuy & Curtidor & Parroquia de Belén & $20 / 06 / 1640$ \\
\hline 5 & Diego Quispe & Cerrajero y Herrero & Pueblo de Coya & $24 / 12 / 1650$ \\
\hline 6 & Pasqual Guaman & Panadero & Parroquia de San Blas & $30 / 09 / 1650$ \\
\hline 7 & Don Juan Ramos & Maestro Platero & Parroquia de Santiago & $10 / 06 / 1650$ \\
\hline 8 & Gavriel Quispe & Maestro Serero & Parroquia de San Cristobal & $20 / 09 / 1640$ \\
\hline 9 & Juan Paucar & Oficial Confitero & Pueblo de Atun Papres & $09 / 01 / 1640$ \\
\hline 10 & Mateo Gualpa & Oficial Cantero & Pueblo de Puquiura & $23 / 07 / 1650$ \\
\hline 11 & Diego Quispe & Cordonero & Parroquia de Santa Ana & $15 / 02 / 1640$ \\
\hline 12 & Miguel Ynga Paucar & Hacedor de tejas & Parroquia de San Sevastian & $23 / 03 / 1650$ \\
\hline 13 & Pedro juan tinco & Cornetista & De esta ciudad & $14 / 02 / 1620$ \\
\hline
\end{tabular}

(16) ARC, Notarios, Alonso Calvo. (1639-1640). Protocolo: 44, Registro Nro. 6. Folio: 23 (reverso).

(17) ARC, Notarios, Alonso Calvo. (1639-1640). Protocolo: 44, Registro Nro. 8. Folio: s/f. 


\begin{tabular}{|c|l|c|c|c|}
\hline 14 & Diego Felipe indio & Organista & Parroquia de San Blas & 09/03/1630 \\
\hline 15 & Francisco Quispe & Maestro Harpero & & $14 / 06 / 1650$ \\
\hline 16 & Don Pedro Paucar & Maestro Cantor & Pueblo de Oropesa & $15 / 07 / 1650$ \\
\hline 17 & Mateo Amao & Sastre & Parr. Hospital de Naturales & $03 / 08 / 1620$ \\
\hline 18 & Ysabel sisa india & Panadera & & $29 / 03 / 1650$ \\
\hline 19 & Joan Pulicarpo & Panadero & Pueblo de Chinchero & $21 / 05 / 1640$ \\
\hline 20 & Carlos Guanca & Mercachifle & Parr. Hospital de Naturales & $24 / 11 / 1640$ \\
\hline 21 & Don Alonso Mayta & Maestro Ministral & & $17 / 11 / 1620$ \\
\hline 22 & Sebastian Ysidro & Sacristán de la & & $08 / 10 / 1640$ \\
\hline 23 & Juan Bautista & Maestro Cerrajero & Residente en el Cusco & $14 / 01 / 1640$ \\
\hline 24 & Don Juan Chauca & Oficial Pintor & Parroquia de San Sebastian & $03 / 03 / 1620$ \\
\hline 25 & Joan Tito & Maestro Sillero & & $21 / 08 / 1640$ \\
\hline 26 & Francisco Guamancuy & Pastelero & & $16 / 03 / 1620$ \\
\hline 27 & $\begin{array}{l}\text { Geronimo Anticussi y } \\
\text { Barbola Pozo su mujer }\end{array}$ & Carniceros & Parroquia de San Sebastian & $12 / 10 / 1630$ \\
\hline
\end{tabular}

Fuente: ARC, Notarios, Alonso Calvo. Prot. 44-45, Antonio Salas. Prot. 293, Domingo de Oro. Prot. 252, Francisco Hurtado. Prot. 119, Joseph Calvo. Prot. 52, Joseph Navarro. Prot. 240, Joseph Solorzano. Prot. 308, Juan Flores de Bastidas. Prot. 96, Lorenzo Messa Andueza. Prot. 177, Lucero Alonso Beltran. Prot. 1 y 7, y Martin Lopez de Paredes. Prot. 135. (Elaboración propia).

Como ya se indicó líneas arriba, la necesidad de mano de obra en la época colonial era apremiante en las nacientes ciudades, dada esta necesidad se tuvo que echar mano de los indígenas varones a quienes se les brindó la oportunidad de poder aprender uno de los tantos oficios del cuadro antes expuesto. En cuanto a las mujeres básicamente las hallamos realizando oficios como panaderas y carniceras.

Pese a que las mujeres indígenas no podían acceder a aprender oficios (como si lo hicieron los indígenas del género masculino), ellas participaron activamente en la acomodación de las nuevas condiciones laborales socioeconómicas coloniales. Esta acomodación se traduce en que ellas mismas, en su condición de madres, aprovecharon estas oportunidades para sus hijos varones (menores de edad), asentándolos como aprendices de los maestros y oficiales en las diferentes artes impartidas en nuestra época de estudio:

"... parecio un yndia... dixo llamarse maria çiça y ser natural della que consertava y conserto a diego dure su hijo nino de hasta doze años poco mas o menos con lucas martin de guzman maestro çapatero tiempo de tres años que an de correr y contarsse desde oy dia de la fecha desta escriptura en adelante para aprendiz del 
dicho oficio Le a de enseñar el dicho oficio que al fin de los dichos tres años sea oficial Le a de curar sus enfermedades como no sean contaxiossas y darle de comer y bestir los dos años de pañete medias y çapatos como fuere rronpiendo y el ultimo año un bestido entero de paño de quito calson rropilla y sombrero medias y capato y una petaquilla del dicho oficio (30/04/1640)."(18)

Como se aprecia en el documento antes expuesto, Diego Dure de 12 años (menor de edad), fue desprendido de su familia (por su madre) y se integró a la vida laboral de la mano de su maestro, todo esto con el objetivo de poder acceder a mejores oportunidades económico laborales en el futuro.

2. Las posibilidades laborales para las mujeres indígenas eran prioritariamente relacionadas a labores domésticas (cocineras, lavanderas, chicheras, nanas o amas de leche):

\subsection{Las amas de leche}

El género femenino indígena se desempeñó en la labor de "Ama de Leche" o "Nodriza", para tratar acerca de esta labor contamos con 40 documentos (fondo notarial). El estado civil de las amas de leche fue: 25 solteras, 13 casadas y 2 viudas:

"... parecio un yndia... dixo llamarse juana larba y ser soltera y natural del pueblo de cuchiguaray provincia de los chilques suxeta a el cacique don Rohusno gualpa consierta con doña tomasa rrodriguez del corral muger soltera rresidente en esta ciudad por tiempo de un año que a de correr y contarsse desde oy dia de la fecha para servir a la suso dicha de ama de leche criando un niño hijo suyo por el precio de doze pesos de a ocho rreales y dos piecas de rropa de avasca y lliclla y dos faldellines de cordellate y a quenta del dicho ssalario confeso aver rrescivido seis pessos de la dicha pLata(19/01/1640)." (19)

Los contratantes de los servicios de las amas de leche para la atención de sus menores hijos (Cuadro Nro. 2), se ubican en el siguiente orden: personas que no indican su condición socio-económica, vecinos, indígenas y aquellos españoles que ostentaron cargos políticos y los comerciantes de la época (mercaderes).

\section{CUADRO Nro. 2: CONTRATANTES DE LAS AMAS DE LECHE}

\begin{tabular}{|c|c|c|c|c|}
\hline No especifican & Vecinos & Indígenas & Cargos políticos & Comerciantes \\
\hline 26 & 6 & 3 & 3 & 2 \\
\hline
\end{tabular}

(18) ARC, Notarios, Joseph Navarro. (1640). Protocolo: 240, Registro Nro. 9. Folio: 507.

(19) ARC, Notarios, Francisco Ruiz Negrete. (1640). Protocolo: 289, Registro Nro. 2. Folio: 68 (reverso). 
Fuente: ARC, Notarios, Alonso Calvo. Prot. 44, Francisco Ruiz Negrete. Prot. 289, Joseph Calvo. Prot. 52, Joseph Navarro. Prot. 240, Juan Flores de Bastidas. Prot. 96, Lorenzo Messa Andueza. Prot. 177, Martin Lopez de Paredes. Prot. 135. (Elaboración propia).

Las "amas de leche" indígenas eran contratadas por las propias madres de los menores de edad (algunos eran huérfanos). Una restricción de este empleo era que no debían embarazarse durante la prestación del servicio. Las tareas que debían cumplir fueron:

1. Servirle y criar una niña a los pechos dandola de mamar buena leche Sana y entera limpiandola con mucho cuydado y Vigilançia teniendo cuydado de todo aquello que se le entregare y fuere a su cargo (23/05/1650). ${ }^{(20)}$

2. Criar a sus pechos con leche entera una nina su hija y a de cuidar con todo cuydado de la limpieça y crianza de la dicha niña sin que en ello tenga otro embaraso ni ynpedimiento $(17 / 11 / 1650){ }^{\text {(21) }}$

3. Criar Un nino guerfano a sus pechos dando leche entera $Y$ cuYdarle de todo ness ${ }^{\circ}$ (necesario) a su criança (23/05/1650). (22)

El espacio de tiempo que laboraba una indígena como ama de leche (Cuadro $\mathrm{N}^{\text {ro. } 3), ~ o s c i l a b a ~ e n t r e ~ l o s ~} 6$ meses hasta los 2 años, pero mayormente, por 1 año y 1 año y medio.

\section{CUADRO NrO. 3: TIEMPO DE TRABAJO DE LOS AMAS DE LECHE}

\begin{tabular}{|c|c|c|c|c|}
\hline 1 año & 1 año con 6 meses & 6 meses & 2 años & 8 meses \\
\hline 19 & 15 & 2 & 3 & 1 \\
\hline
\end{tabular}

Fuente: ARC, Notarios, Alonso Calvo. Prot. 44, Francisco Ruiz Negrete. Prot. 289, Joseph Calvo. Prot. 52, Joseph Navarro. Prot. 240, Juan Flores de Bastidas. Prot. 96, Lorenzo Messa Andueza. Prot. 177, y Martin Lopez de Paredes. Prot. 135. (Elaboración propia).

En salario anual de las amas de leche fue monetario y no monetario. Fluctuaba entre los 12 pesos (más 2 piezas de ropa de abasca, 1 lliclla, y 2 faldellines de cordellate), hasta los 20 pesos (más 2 piezas de ropa de abasca, 2 faldellines de pañete azul, 1 chumbe, las ojotas que rompiere y de comer) y el salario de 1 año y medio fluctuó entre los 12 pesos (más 2 piezas de ropa una de tasa y la otra de hechura, 2 faldellines de pañete, 1 ñañaca de anascote, 1 faja, las ojotas que rompiere y de comer), hasta los 40 pesos (más, 2 piezas de ropa de abasca, 2 faldellines el uno de paño de quito y el otro de pañete, las ojotas que rompiere y de comer).

(20) ARC, Notarios, Juan Flores de Bastidas. (1649-50). Protocolo: 96, Registro Nro. 7. Folio: 304.

(21) ARC, Notarios, Juan Flores de Bastidas. (1649-50). Protocolo: 96, Registro Nro. 7. Folio: 393 (rev).

(22) ARC, Notarios, Juan Flores de Bastidas. (1649-50). Protocolo: 96, Registro Nro. 6. Folio: 244. 


\subsection{Las empleadas domésticas}

La denominación empleada doméstica no está consignada en los documentos de archivo. Sin embargo, textualmente describen la labor a realizar; "le servirle en su casa y fuera de ella en todo aquello que le mandare y ocupare", por lo que, en adelante, denominaremos a esta función como "empleada doméstica" (contamos con 43 documentos de archivo). En cuanto al estado civil de las mismas, tenemos: 25 solteras, 14 casadas y 4 viudas:

“.. Paresçio Una yndia... Dixo llamarse maria pilco y ser naturaL de La parroquia de san Geronimo concertó con esteVan dasa rresidente En La dha (dicha) parroquia de san geronimo Donde asiste Con su muger y familia tiempo de seis meses que an de Correr y Contarse Desde primero De jullio que Vendra Deste presente año para de servir aL suso dho (dicho) en su casa de toDo aquello en que La quisiere ocupar y Le mandare a que a de acudir con toda puntualidad por el precio de quatro rreaLes y medio cada semana y para en quenta de Lo que montare confiesa aVer rresçeviDo... catorçe pessos de a ocho (21/06/1650).,(23)

Las contratantes de las empleadas domésticas (Cuadro Nro. 4) fueron prioritariamente, personas que no especifican su condición socio-económica, indígenas (prioritariamente mujeres indígenas), vecinos, personas que ostentaron cargos políticos y mestizos.

\section{CUADRO Nro. 4: CONTRATANTES DE LAS EMPLEADAS DOMÉSTICAS}

\begin{tabular}{|c|c|c|c|c|}
\hline No especifican & Indígenas & Vecinos & Cargos políticos & Mestizos \\
\hline 27 & 8 & 4 & 3 & 1 \\
\hline
\end{tabular}

Fuente: ARC, Notarios, Alonso Calvo. Prot. 44, Domingo de Oro. Prot. 264, Francisco Ruiz Negrete. Prot. 289, Joseph Navarro. Prot. 240, Juan Flores de Bastidas. Prot. 96, y Lorenzo Messa Andueza. Prot. 177. (Elaboración propia).

En cuanto a las tareas a cumplir de las empleadas domésticas (indígenas) tenemos:

1. Servirla en su casa en todo aquello que la mandare $Y$ se le encargare en su casa (11/05/1650). ${ }^{(24)}$

2. Servirle En su cassa y fuera della en todo lo que se le mandare y quisiere ocupar (26/04/1640). ${ }^{(25)}$

(23) ARC, Notarios, Juan Flores de Bastidas. (1649-50). Protocolo: 96, Registro Nro. 7. Folio: 324.

(24) ARC, Notarios, Juan Flores de Bastidas. (1650). Protocolo: 96, Registro Nro. 7. Folio: 293.

(25) ARC, Notarios, Alonso Calvo. (1640). Protocolo: 44, Registro Nro. 6. Folio: 82 
3. Servir aL suso dho (dicho) en su casa de toDo aquello en que La quisiere ocupar y Le mandare a que a de acudir con toda puntualidad (21/06/1650). (26)

El espacio de tiempo que laboraron las empleadas domésticas (Cuadro Nro. 5), oscilaba entre los 6 meses hasta 6 años. Aunque, prioritariamente, concertaron sus servicios por 1 año.

\section{CUADRO Nro. 5: TIEMPO DE TRABAJO DE LAS EMPLEADAS DOMÉSTICAS}

\begin{tabular}{|c|c|c|c|c|}
\hline 1 año & 6 meses & 2 años & 6 años & 1 año y medio \\
\hline 37 & 3 & 1 & 1 & 1 \\
\hline
\end{tabular}

Fuente: ARC, Notarios, Alonso Calvo. Prot. 44, Domingo de Oro. Prot. 264, Francisco Ruiz Negrete. Prot. 289, Joseph Navarro. Prot. 240, Juan Flores de Bastidas. Prot. 96, y Lorenzo Messa Andueza. Prot. 177. (Elaboración propia).

La remuneración anual fue monetaria y no monetaria y la cantidad percibida por las empleadas domésticas indígenas en la ciudad del Cusco oscilaba entre los 10 pesos (más, 1 pieza de ropa de abasca, chumbes, ojotas que rompiere, de comer y buen trato) hasta los 50 pesos (más 3 cargas de maíz). Para el caso de Lima en el siglo XVII, las servidoras domesticas obtenían como salario "techo, alimentación y, eventualmente un pago que, aunque bajo, les permitía satisfacer algunas necesidades, incluyendo obligaciones tributarias. Según los asientos de contratos en los protocolos notariales, a partir del gobierno de Toledo el trabajo era evaluado en 12 pesos además de vivienda, alimentación y vestido."(27) Miguel Glave (1989) ha encontrado que "este pago fluctuaba entre 5 a 24 pesos anuales. En algunos casos incluía la ropa y el calzado."(28)

\subsection{Las cocineras y lavanderas}

En los contratos de trabajo (documentos de archivo) se consigna que las mujeres indígenas fueron contratadas para laborar como cocineras o lavanderas (individualmente) o, en su defecto, para cumplir ambas funciones. La mujer y la cocina aparecen en una relación inmutable en el tiempo y quizás sea la permanencia de este vínculo entre lo femenino, la elaboración de alimentos y la cocina, el sustrato sobre el cual descansa el oficio alfarero. ${ }^{(29)}$ En cuanto al estado civil de las cocineras y lavanderas tenemos ( 11 documentos): 8 casadas, 2 solteras y 1 viuda.

(26) ARC, Notarios, Juan Flores de Bastidas. (1650). Protocolo: 96, Registro Nro. 7. Folio: 324.

(27) Ormeño, T. V. (1997). Migración y trabajo femenino a principios del siglo XVII: el caso de las indias en Lima. Histórica, 21(1), Pág. 135.

(28) Glave, L. M. (1989). Trajinantes: caminos indígenas en la sociedad colonial: siglos XVI-XVII. Lima: Instituto de apoyo agrario. Pág. 355-357.

(29) LEVI-STRAUSS, Claude. La Alfarera celosa. Barcelona, Buenos Aires, México: Ed. Paidos, 1986. Pág. 76. 
“.. Paresçio una yndia... dixo llamarse maria pasña y ser natural de la parroquia del ospital desta çiudad y con lisençia de sevastian gutierrez su marido yndio natural de la parroquia de san sebastian sujeto a don pedro amao concerto con dona maria francisca ladron de quevara biuda de diego flores tiempo de un año para servir a la suso dicha en su casa de cosinera y en lavar la rropa y en todo lo demas que se le mandare precio de dos pieças de rropa la una de hechura y la otra de tasa un faldellin de paño de quito las ojotas que hubiere menester y el sustento hordinario y diez y seis pesos de a ocho rreales en plata y para en quenta dello a rresçevido... seys pesos (13/09/1650)."(30)

\section{CUADRO Nro. 6: CONTRATANTES DE LAS COCINERAS Y LAVANDERAS}

\begin{tabular}{|c|c|c|c|c|}
\hline No especifican & Vecinos & Indígenas & Cargos políticos & Comerciantes \\
\hline 6 & 2 & 1 & 1 & 1 \\
\hline
\end{tabular}

Fuente: ARC, Notarios, Alonso Calvo. Prot. 44, Joseph Calvo. Prot. 52, Juan Flores de Bastidas. Prot. 96, y Martin Lopez de Paredes. Prot. 135. (Elaboración propia).

Los contratantes de las cocineras y lavanderas indígenas (Cuadro $\mathrm{N}^{\text {ro. }}$ 6), fueron prioritariamente mujeres ubicadas en el rubro de las que no especifican su condición socio-económica, vecinos, personas que ostentaron cargos políticos, indígenas y comerciantes (mercaderes). Las funciones que debían cumplir fueron:

1.-Le servir de cosinera y en todo lo demas que se le mandare y ocupare $(16 / 01 / 1640)^{(31)}$

2.-Servirle en su cassa y fuera della de cosinera y lavandera y en todo lo que se le mandare y dara quenta con pago de todo lo que se le entregare (01/06/1650). ${ }^{\text {(32) }}$

El espacio de tiempo en el que laboraron (Cuadro $\mathrm{N}^{\text {ro. }}$ 7), oscilaba entre los 6 meses hasta los 2 años, pero, prioritariamente, por espacio de 1 año.

\section{CUADRO Nro. 7: TIEMPO DE TRABAJO DE LAS COCINERAS Y LAVANDERAS}

\begin{tabular}{|c|c|c|}
\hline $\mathbf{1}$ año & $\mathbf{6}$ meses & $\mathbf{2}$ años \\
\hline 9 & 1 & 1 \\
\hline
\end{tabular}

Fuente: ARC, Notarios, Alonso Calvo. Prot. 44, Joseph Calvo. Prot. 52, Juan Flores de Bastidas. Prot. 96, y Martin Lopez de Paredes. Prot. 135. (Elaboración propia).

(30) ARC, Notarios, Juan Flores de Bastidas. (1649-1650). Protocolo: 96, Registro Nro. 5. Folio: 353.

(31) ARC, Notarios, Alonso Calvo. (1640). Protocolo: 44, Registro Nro. 6. Folio: 23 (reverso).

(32) ARC, Notarios, Martin Lopez de Paredes. (1650). Protocolo: 135, Registro Nro. 16. Folio: 923. 
La remuneración (monetaria y no monetaria) anual de una indígena cocinera y lavandera oscilaba entre los 15 pesos (más 1 faldellín de paño de quito, 1 pieza de ropa de abasca ${ }^{(33)}\left(\mathrm{acsu}^{(34)}\right.$, lliclla ${ }^{(35)}$ y una ñañaca $\left.{ }^{(36)}\right)$, seis pares de ojotas y de comer) hasta los cincuenta pesos (más medio real para su comida).

\subsection{Las chicheras}

Con respecto a la chicha debemos indicar que, en el mundo prehispánico, la chicha fue un componente esencial en los rituales indígenas. Aparte de la chicha destinada al común, hubo un tipo especial que servía para el culto. Su elaboración fue una actividad muy importante que estuvo en manos de gente especializada. ${ }^{(37)}$ Por su parte Vergara menciona que, en el periodo colonial, fueron mayormente las indias las que continuaron preparando la chicha, bebida que por su gran demanda entró pronto a circular en el mercado. ${ }^{(38)}$ En consecuencia, la elaboración y venta de chicha representó un negocio rentable debido a que esta bebida era consumida por el grueso de la población indígena.

Particularmente en la ciudad del Cusco, las mujeres indígenas fueron las que prioritariamente laboraron como "chicheras". Sin embargo, cabe señalar que esta actividad no fue exclusiva de las mujeres, pues, los indígenas varones también concertaron sus servicios para preparar esta bebida. En cuanto al estado civil de las chicheras tenemos ( 11 documentos): 5 casadas y 5 solteras:

“... Paresçio una yndia... dixo llamarse maria de las nieves y sser casada con juan yupanqui y que a muchos años que anda ausente desta çiudad sin saver donde pueda estar y que es natural de la parroquia de san xptoval concerto con paula de barrios buida de pedro ximenes tiempo de un año que a de empesar a correr y contarse desde veynte y quatro deste dicho mes para servir a la suso dicha y haser chicha de una carga de mays que le a de dar en cada semana y todos los rrecados necesarios para hasserla de forma que no a de poner en ello mas de traer el agua coser la chicha y venderla y de dar seys pesos de cada carga precio de treynta pesos en rreales y

(33) K'uilkuy k'uilkuy. loc. Fina e igualmente torzalado, muy bien torzalado. EJEM: k'uilkuy k'ullkuy awasqa, finamente tejido. (J.L.P.) Pe.Aya: tullkuy tullkuy. Gobierno Regional del Cusco. (2005). Diccionario Quechua - Español - Quechua. Segunda ed., Cusco - Perú. Pág. 136.

(34) Aksu. s. tej. Vestido inka. Camiseta de mujer, ajustado al cuerpo, que dejaba ver las piernas. SINÓN: kusma. (D.G.H.) || V. ANA. Ídem. Pág. 18.

(35) Lliklla. s. Manta tejida de hilos de lana y colores vivos, usada como mantilla por las campesinas de la sierra. Presenta decoraciones características de acuerdo a su pueblo de procedencia. Bol: llijlla. Ídem. Pág. 151.

(36) Ñañaka. s. tej. Tejido rectangular o cuadrangular que llevan las mujeres a la cabeza, hermosamente pintadas y bordadas. SINÓN: iskayo. Ídem. Pág. 191.

(37) Ormeño, T. Óp. cit. p. 150-151.

(38) Ídem. p. 151. 
una fanega de mays para su sustento y para en quenta de su salario a rresçevido... diez pessos de a ocho (23/09/1650). ${ }^{(39)}$

Las personas que contrataron a las indígenas "chicheras" (Cuadro Nro. 8), primordialmente fueron personas de ambos géneros que no especifican su condición socio-económica y los comerciantes de la época (mercaderes).

\section{CUADRO Nro. 8: CONTRATANTES DE LAS CHICHERAS}

\begin{tabular}{|c|c|}
\hline No especifican & Comerciantes \\
\hline 8 & 3 \\
\hline
\end{tabular}

Fuente: ARC, Notarios, Alonso Calvo. Prot. 44, Joseph Calvo. Prot. 52, Juan Flores de Bastidas. Prot. 96, y Martin Lopez de Paredes. Prot. 135. (Elaboración propia).

Las chicheras tenían que cumplir las tareas siguientes:

1. Servirla en su cassa de chichera sacando de carga y media de mais en chicha cada semana y bendiendola dandosele todo el rrecaudo nesesario para ello y de lo que asi bendiere dara quenta con pago (10/10/1650). ${ }^{(40)}$

2. Servirle en su cassa o fuera della en hacer chicha cada semana se le a de sacar dos cargas y para ello le a de dar todo lo necesario y una yndia que le ayude en hacer chicha y dara quenta de todo lo que se le entregare (02/05/1650). ${ }^{(41)}$

3. Servirle en vender chicha en la plaza de limapampa cada semana dos cargas de chicha (02/03/1650). ${ }^{(42)}$

4. Hacerchichaen su cassa y fuera della yen todolo que sele mandare (28/09/1650). ${ }^{\text {(43) }}$

Como podemos apreciar, en algunos casos las chicheras indígenas, eran contratadas para la preparación y venta de la chicha, en otros casos sólo como vendedoras (en las plazas de la ciudad o en su defecto en las casas de los contratantes). El tiempo de trabajo (Cuadro Nro. 9) oscilaba entre 1 hasta 2 años, pero, prioritariamente, por 1 año.

\section{CUADRO Nro. 9: TIEMPO DE TRABAJO DE LAS CHICHERAS}

\begin{tabular}{|c|c|}
\hline $\mathbf{1}$ año & $\mathbf{2}$ años \\
\hline 10 & 1 \\
\hline
\end{tabular}

(39) ARC, Notarios, Juan Flores de Bastidas. (1649-1650). Protocolo: 96, Registro Nro. 8. Folio: 359.

(40) ARC, Notarios, Juan Flores de Bastidas. (1649-1650). Protocolo: 96, Registro Nro. 8. Folio: 368.

(41) ARC, Notarios, Martin Lopez de Paredes. (1650). Protocolo: 135, Registro Nro. 16. Folio: 892.

(42) ARC, Notarios, Martin Lopez de Paredes. (1650). Protocolo: 135, Registro Nro. 16. Folio: 855 reverso.

(43) ARC, Notarios, Martin Lopez de Paredes. (1650). Protocolo: 135, Registro Nro. 17. Folio: s/f. 
Fuente: ARC, Notarios, Alonso Calvo. Prot. 44, Joseph Calvo. Prot. 52, Juan Flores de Bastidas. Prot. 96, y Martin Lopez de Paredes. Prot. 135. (Elaboración propia).

La remuneración anual de las chicheras fue monetaria y no monetaria, fluctuó entre los 20 pesos (más 1 fanega de maíz, 1 pieza de ropa de abasca y 1 faldellín de pañete) hasta los 50 pesos (más 1 pieza de ropa y 1 carga de maíz).

\section{Mujeres indígenas no subordinadas a nivel laboral}

Algunas mujeres indígenas incursionaron y se incorporaron activamente al mercado laboral de la colonia, como una forma de ayuda a sus familias, pero también como una forma de resistencia activa. Las mujeres no subordinadas a nivel laboral, se caracterizaron por ser ellas quienes contrataban los servicios de otros indígenas, algunas pertenecieron a la elite indígena cusqueña y las emprendedoras cusqueñas del común como Ysabel Sisa (panadera), Barbola Pozo (carnicera) e Ysabel Cisa (costurera).

\section{CUADRO Nro. 10: MUJERES INDÍGENAS (CONTRATANTES)}

\begin{tabular}{|c|c|c|c|c|c|c|}
\hline $\mathrm{N}^{\circ}$ & Contratante & $\begin{array}{c}\text { Contratada } \\
\text { (0) }\end{array}$ & $\begin{array}{l}\text { Trabajo a } \\
\text { realizar }\end{array}$ & Tро. & Salario & Fecha \\
\hline 1 & $\begin{array}{l}\text { Juana } \\
\text { Poya yndia } \\
\text { Parroquia de } \\
\text { San Xpoval }\end{array}$ & $\begin{array}{l}\text { Bernave } \\
\text { Consa } \\
\text { del Pueblo de } \\
\text { Santa Lucia }\end{array}$ & $\begin{array}{l}\text { Servirle En su } \\
\text { cassa y fuera } \\
\text { della En todo } \\
\text { lo que se le } \\
\text { mandare }\end{array}$ & 1 año & $\begin{array}{l}50 \text { pesos corrientes de a ocho } \\
\text { de los quales a de bestir y le a } \\
\text { de dar de comer y no otra cosa } \\
\text { mas y para en quenta deste dicho } \\
\text { consierto confeso... aver rrescevido } \\
\text { adelantados } 5 \text { pesos }\end{array}$ & $\begin{array}{l}09 / 03 / \\
1640\end{array}$ \\
\hline 2 & $\begin{array}{l}\text { Juana } \\
\text { Chucllo } \\
\text { Yndia }\end{array}$ & $\begin{array}{l}\text { Ynes Sisa de } \\
\text { la Parroquia } \\
\text { de San } \\
\text { Jeronimo }\end{array}$ & $\begin{array}{l}\text { Le servir en } \\
\text { todo aquello } \\
\text { que dentro e } \\
\text { fuera de ssu } \\
\text { cassa Les } \\
\text { mandare. }\end{array}$ & 1 año & $\begin{array}{l}15 \text { pesos y dos cargas de maiz y } \\
\text { una pieça de rropa }\end{array}$ & $\begin{array}{l}26 / 03 / \\
1640\end{array}$ \\
\hline 3 & $\begin{array}{l}\text { Juana } \\
\text { Chucllo } \\
\text { yndia }\end{array}$ & $\begin{array}{l}\text { Lorença } \\
\text { Sisa de la } \\
\text { Parroquia de } \\
\text { San Jeronimo }\end{array}$ & $\begin{array}{l}\text { Le servir en } \\
\text { todo aquello } \\
\text { que dentro e } \\
\text { fuera de ssu } \\
\text { cassa Les } \\
\text { mandare } \\
\end{array}$ & 1 año & $\begin{array}{l}15 \text { pesos y dos cargas de maiz y } \\
\text { una pieça de rropa }\end{array}$ & $\begin{array}{l}26 / 03 / \\
1640\end{array}$ \\
\hline 4 & $\begin{array}{l}\text { Doña Ysabel } \\
\text { Guaco Ocllo }\end{array}$ & $\begin{array}{l}\text { Ursula cissa } \\
\text { del Pueblo de } \\
\text { Sumaro }\end{array}$ & $\begin{array}{l}\text { Servir En su } \\
\text { cassa En todo } \\
\text { loque se le } \\
\text { mandare }\end{array}$ & 1 año & $\begin{array}{l}10 \text { pesos corrientes de a ocho } \\
\text { rreales El peso y una piesa de rropa } \\
\text { de abasca y chumbes y ojotas que } \\
\text { pudiere rromper y de comer y hara } \\
\text { todo buen tratamiento }\end{array}$ & $\begin{array}{l}16 / 04 / \\
1640\end{array}$ \\
\hline
\end{tabular}




\begin{tabular}{|c|c|c|c|c|c|c|}
\hline 5 & \begin{tabular}{|l} 
Ysavel \\
Cissa yndia \\
panadera
\end{tabular} & $\begin{array}{l}\text { Andres } \\
\text { Quispe } \\
\text { de la } \\
\text { Parroquia de } \\
\text { San Blas }\end{array}$ & $\begin{array}{l}\text { Le servir en } \\
\text { el ministerio } \\
\text { de la dicha } \\
\text { panaderia } \\
\text { y en todo } \\
\text { aquello que } \\
\text { le mandare y } \\
\text { ocupare }\end{array}$ & 1 año & $\begin{array}{l}60 \text { pessos y cuando amase le a } \\
\text { de dar de rracion tres panes y a } \\
\text { rrescivido los dicho } 60 \text { pessos para } \\
\text { pagar sus deudas de que se dio por } \\
\text { contento y entregado a su voluntad }\end{array}$ & $\begin{array}{l}31 / 04 / \\
1640\end{array}$ \\
\hline 6 & $\begin{array}{l}\text { Lorenço } \\
\text { Paucar } \\
\text { Organista } \\
\text { y Francisca } \\
\text { Ocllo }\end{array}$ & $\begin{array}{l}\text { Lucia Uma } \\
\text { soltera del } \\
\text { Pueblo de } \\
\text { Oropessa }\end{array}$ & $\begin{array}{l}\text { Le servir en } \\
\text { su cassa y } \\
\text { fuera della en } \\
\text { todo lo que } \\
\text { le mandare y } \\
\text { ocupare }\end{array}$ & 1 año & $\begin{array}{l}30 \text { pessos de a ocho una piessa de } \\
\text { rropa de avasca y las ojotas que } \\
\text { rrompiere y para en quenta confeso } \\
\text { aver rrescivido } 11 \text { pessos de que se } \\
\text { dio por contenta y entregada a su } \\
\text { voluntad }\end{array}$ & $\begin{array}{l}04 / 07 / \\
1640\end{array}$ \\
\hline 7 & $\begin{array}{l}\text { Doña } \\
\text { Susana Asto } \\
\text { Chumbe } \\
\text { muger de } \\
\text { Don Joan } \\
\text { Nauton de la } \\
\text { Parroquia de } \\
\text { Santa Ana }\end{array}$ & $\begin{array}{l}\text { Francisca } \\
\text { Payco de la } \\
\text { Parroquia de } \\
\text { Señora de } \\
\text { Santa Ana }\end{array}$ & $\begin{array}{l}\text { ServiLLe en } \\
\text { su cassa en } \\
\text { todo lo que le } \\
\text { mandare y se } \\
\text { ofreciere }\end{array}$ & 1 año & $\begin{array}{l}25 \text { pessos corrientes de a ocho } \\
\text { rreales el peso en rreales y una pieça } \\
\text { de rropa de avasca y un faldellin } \\
\text { de pañete ac,ul y un chumbe y dos } \\
\text { paresa de ojotas y tres cargas de } \\
\text { maiz para su comer y a quenta del } \\
\text { dicho servicio confeso aver rrescivido } \\
15 \text { pessos de a ocho }\end{array}$ & $\begin{array}{l}17 / 08 / \\
1640\end{array}$ \\
\hline 8 & $\begin{array}{l}\text { Francisca } \\
\text { Ocllo de la } \\
\text { Parroquia } \\
\text { del Ospital }\end{array}$ & $\begin{array}{l}\text { Juana Cisa } \\
\text { soltera natural } \\
\text { del Pueblo de } \\
\text { Urubamba }\end{array}$ & $\begin{array}{l}\text { Le servir en } \\
\text { todo lo que } \\
\text { le mandare y } \\
\text { ocupare. }\end{array}$ & 1 año & $\begin{array}{l}20 \text { pessos y una piesa de rropa de } \\
\text { avasca dos cargas de maiz y para } \\
\text { en quenta confeso aver rrescevido } \\
10 \text { pesos }\end{array}$ & $\begin{array}{l}04 / 09 / \\
1640\end{array}$ \\
\hline 9 & $\begin{array}{l}\text { Susana } \\
\text { Asiuchunjur }\end{array}$ & $\begin{array}{l}\text { Francisco } \\
\text { Naupa } \\
\text { del Pueblo de } \\
\text { Puquiura }\end{array}$ & $\begin{array}{l}\text { Le servir en } \\
\text { todo quanto } \\
\text { le mandare y } \\
\text { quisiere ocupar }\end{array}$ & 1 año & $\begin{array}{l}25 \text { pessos en rreales una pieca de } \\
\text { rropa calson manta y camixeta tres } \\
\text { cargas de maiz para su sustento y } \\
\text { a quenta del dicho salario confeso } \\
\text { aver rrescibido los dichos } 25 \text { pessos } \\
\text { adelantados }\end{array}$ & $\begin{array}{l}17 / 09 / \\
1640\end{array}$ \\
\hline 10 & $\begin{array}{l}\text { Ysabel } \\
\text { Cisa muger } \\
\text { soltera de la } \\
\text { Parroquia de } \\
\text { Santa Ana }\end{array}$ & $\begin{array}{l}\text { Pedro Ylla } \\
\text { de la } \\
\text { Parroquia de } \\
\text { Santa Ana }\end{array}$ & $\begin{array}{l}\text { Le servir en su } \\
\text { casa y fuera } \\
\text { della en todo } \\
\text { lo que se le } \\
\text { mandare y } \\
\text { quisiere ocupar } \\
\text { en su casa y } \\
\text { fuera della y en } \\
\text { hazer calçones } \\
\text { sin hazer } \\
\text { fallas. } \\
\end{array}$ & 1 año & $\begin{array}{l}43 \text { pesos en Reales y dellos a } \\
\text { de comer y bestir para en quenta } \\
\text { dellos confiesa aver Rescibido } 12 \\
\text { pesos corrientes de a ocho el peso } \\
\text { adelantados }\end{array}$ & $\begin{array}{l}03 / 10 / \\
1640\end{array}$ \\
\hline 11 & $\begin{array}{l}\text { Francisca } \\
\text { Carua de la } \\
\text { Parroquia de } \\
\text { Santa Ana }\end{array}$ & $\begin{array}{l}\text { Sebastina } \\
\text { Cillo de la } \\
\text { Parroquia de } \\
\text { san Geronimo }\end{array}$ & $\begin{array}{l}\text { Le servir de } \\
\text { cosinera y } \\
\text { labandera en } \\
\text { su cassa y } \\
\text { fuera della }\end{array}$ & $\begin{array}{c}6 \\
\text { meses }\end{array}$ & $\begin{array}{l}\text { veinte y cinco pessos corrientes de } \\
\text { a ocho y de comer y para En quenta } \\
\text { confeso aver rrecevido } 11 \text { pessos y } \\
2 \text { rreales }\end{array}$ & $\begin{array}{l}02 / 11 / \\
1640\end{array}$ \\
\hline
\end{tabular}




\begin{tabular}{|c|l|l|l|c|l|l|}
\hline 12 & $\begin{array}{l}\text { Ysavel Ulpa } \\
\text { Palla }\end{array}$ & $\begin{array}{l}\text { Andres Villca } \\
\text { del Pueblo de } \\
\text { Yanquesupa }\end{array}$ & $\begin{array}{l}\text { Le servirle en } \\
\text { todo lo que le } \\
\text { mandare. }\end{array}$ & $\begin{array}{c}2 \text { años } \\
\text { y } 1 / 2\end{array}$ & 132 pessos de a ocho rreales & $\begin{array}{l}21 / 11 / \\
1640\end{array}$ \\
\hline 13 & $\begin{array}{l}\text { Petrona } \\
\text { Ocllo }\end{array}$ & $\begin{array}{l}\text { Agustina } \\
\text { Chaves } \\
\text { del Pueblo de } \\
\text { Acomayo }\end{array}$ & $\begin{array}{l}\text { Servirle de } \\
\text { ama y criarle a } \\
\text { un niño y darle } \\
\text { la leche con } \\
\text { todo cuydado y } \\
\text { limpieça }\end{array}$ & 1 año & $\begin{array}{l}13 \text { pesos de a oho rreales y una } \\
\text { piesa de rropa de abasca hechura } \\
\text { y otra pieça de rropa de abasca ya } \\
\text { traido y dos faldellines de pañete } \\
\text { nuevas y de comer y para en quenta } \\
\text { confeso aver Recevido 4 pesos }\end{array}$ & $\begin{array}{l}23 / 03 / \\
1650\end{array}$ \\
\hline
\end{tabular}

Fuente: ARC, Notarios, Alonso Calvo. (1639-1640). Prot. 44. Registro Nro. 6. Folios: 50 y 71 (reversos), Registro Nro. 7. Folio: s/f, Registros Nros. 8 - 10. Folios: s/f (4), Francisco Ruiz Negrete. (1640). Prot. 289, Registro Nro. 5. Folio: 260, y Registro Nro. 11. Folio: 499 (reverso), Joseph Navarro. (1640). Prot. 240. Registro Nro. 14. Folio: 806, Lucero Alonso Beltran. (16401641). Prot. 7. Registro Nro. 11. Folio: 643, y Martin Lopez de Paredes. (1650). Prot. 135. Registro Nro. 16. Folio: 869 (Reverso). (Elaboración propia).

\subsection{Mujeres de la elite indígena cusqueña (contratantes)}

Podemos identificar a mujeres indígenas de la nobleza cusqueña como contratantes de otros indígenas (Cuadro Nro. 10), tenemos los casos de Doña Ysabel Guaco Ocllo y Doña Susana Asto Chumbe.

El caso de Doña Susana Asto Chumbe. - Estaba casada con Don Juan Augustin Nauton, ambos eran provenientes de la Parroquia de Santa Ana. Don Juan Nauton ostentó el cargo de Alcalde de la referida parroquia ${ }^{\text {(44) }}$ y además se dedicó a otras actividades económicas:

"... parecio un yndio ... dixo llamarse pedro sacan natural de la parroquia de santa ana sujeto a don juan ogosicha su casique concerto con don juan nauton por el tiempo de un año que corre y se cuenta desde cinco dias deste presente mes para le servirle de yanacona harriero cargando y descargando una piara de nueve mulas a las partes y lugares que se le mandare por el precio de cinquenta pesos corrientes de a ocho rreales El peso y doze baras de cordellate y Los alpargates que rrompiere y la rracion hordinaria y para en quenta... confeso aver rrescivido diez pesos de que se dio por contento y Entregado a su voluntad (03/03/1640).,"(45)

El siguiente documento fue redactado el once de marzo de 1650:

"... paresçio Un Yndio... dixo llamarse ssantiago guaman natural de la parroquia de santa ana sujeto a don marcos carUa

(44) ARC, Notarios, Juan Flores de Bastidas. (1649-1650). Protocolo: 96, Registro Nro. 6. Folio: 266.

(45) ARC, Notarios, Alonso Calvo. (1639-1640). Protocolo: 44, Registro Nro. 6. Folio: 46 (reverso). 
yañac su cassique concierta con juan augustin nauton alcalde de la dha (dicha) parroquia tiempo de Un año que an de enpesar a correr desde mañana doçe deste dicho mes de março deste pressente año para servirle de harriero peon en las mulas que tiene el dho (dicho) juan augustin nauton $Y$ se Yra a las partes $Y$ lugares a donde le fuere mandado cargando $Y$ descargando Una piara de nuebe mulas por el precio de sesenta pessos $Y$ los alpargates que Ubiere menester $Y$ la rraçion hordinaria para su sustento y mas Una mula ensillada de camino para que el dho (dicho) santiago guaman baya arreando en el $Y$ confeso aver rresçevido diez pessos adelantados."(46)

De los documentos antes expuestos podemos denotar que Don Juan y Doña Susana pertenecieron a la elite indígena cusqueña, esta posición les permitió tener la solvencia económica sufícientemente como para poder contratar a otros indígenas. En el caso de Doña Susana contrata a una indígena para el servicio doméstico en su hogar y Don Juan contrata en 1640 y 1650 arrieros para la atención, cuidado y guiado de su piara de 9 mulas, para 1630 una mula tenía el costo de 50 pesos aproximadamente, es decir, tenían 500 pesos (mulas) sin contar los productos que eran enviados en la piara de mulas.

\subsection{Emprendedoras indígenas cusqueñas}

La consolidación socioeconómica colonial logró su cometido en gran parte gracias a la ayuda del grueso de la población indígena, quienes laboraron (subordinados y no subordinados) en los distintos espacios ofrecidos por el nuevo mercado laboral. En este contexto existieron emprendedoras indígenas (del común) cusqueñas, quienes iniciaron y encaminaron sus propios negocios. Con la ayuda del rastro que permite la documentación registrada de la época, podemos señalar que hubo panaderas, carniceras y costureras. Y las hallamos realizando la contratación de servicios de otros indígenas para que puedan ayudarles en sus negocios y en otras actividades económicas: vendiendo y requiriendo dinero de los mercaderes. Cabe aclarar que no menciono a aquellas que no fueron registradas en los documentos de la época, es decir, aquellas que no requirieron de contratar a otros indígenas (al menos no con un contrato legal) probablemente; dentro de este grupo de mujeres, se hallan los antecedentes de las actuales mujeres del mercado o katu. ${ }^{(47)}$

El caso de Barbola Poço (carnicera), fue una mujer indígena, cuyo cónyuge fue Geronimo Anticussi, ambos carniceros (naturales de la Parroquia de San Sebastián - Cusco). El 22 de septiembre de 1620:

(46) ARC, Notarios, Juan Flores de Bastidas. (1649-1650). Protocolo: 96, Registro Nro. 6. Folio: 266.

(47) Qhatu. s. Mercado, tienda, almacén, venta, puesto de ventas, negocio. SINÓN: churakuy. Pe.Aya: tachiy, rantiy. Pe.Jun: lantina. Ec: katu. Gobierno Regional del Cusco. (2005). Diccionario Quechua - Español - Quechua. Segunda ed., Cusco - Perú. Pág. 256. 
"... pedro salca y francisco cutipa francisco guamay Blas quispe diego cuchu quispe anticussi geronimo anticussi francisco timay condor yndios carniceros rresidentes en esta ciudad conserto con francisco de Ontiveros por tiempo desde veinte de octubre venidero deste presente año para que el suso dicho se obliga de dar y entregar a los dichos carniceros quatro mil carneros de castilla de dos años Para arriba cada mes Un mill dellos puestos y entregados en los pastos de la redonda y jurisdiccion ciudad donde los dichos yndios carniceros le señalasen y el dicho entrego a de hazer. desde veinte de octubre venidero deste presente año y se le ha de dar un yndio pastor para que el dicho ganado en los dichos pastos y los dichos yndios carniceros por el precio Por cada uno dellos Lan de pagar todos juntos a rrazon de a ocho rreales por cada cabeza y en esta forma al fin de cada mes le an de dar quenta con pago de lo que asi gastaren y asi mismo de dar y pagar al dicho yndio michique guardare el dicho ganado cada un dia un real."(48)

El siguiente documento fue redactado el 12 de diciembre de 1630:

"... Nos geronimo anticussi y barbola poço su muger yndios carniceros y yo el suso dicho siego de la vista corporal naturales que ssomos de la parroquia de san sebastian de esta ciudad del cuzco del piru vende a francisca de sandi muger soltera rresidente en esta ciudad que esta presentem un pedaço de solar con dos buhios cubiertos de paxa que e y tenemos en la parroquia de san blas en el asiento de chirripaccha por el precio de ducientos y quarenta y nueve pessos de a ocho el peso que nos da y paga en rreales de contado., ${ }^{\text {(49) }}$

De los documentos antes expuestos podemos denotar que el cónyuge de Barbola Poço se reconocía y se dedicaba a ser carnicero desde 1620. Para 1630 hallamos que participa de la venta de una propiedad ubicada en la Parroquia de San Blas, notamos que ella reside en la parroquia de San Sebastián, pero cuenta con otra propiedad ubicada en otra parroquia.

El caso de Ysabel Sisa (Panadera). - Fue otra emprendedora indígena, su cónyuge fue Pedro Chuque, en los documentos se le denomina yndia panadera. Según, el siguiente documento, Ysabel Sisa contrata a Andrés Quispe para que trabaje en su panadería:

"... parecio un yndio... dixo llamarse andres quispe y ser natural de la parroquia de san blas sujeto a don diego canatopa su casique concierta con ysavel cissa yndia panadera tiempo de un año que a de correry contarse desde oy en adelante para le servir en el ministerio de la

(48) ARC, Notarios, Domingo de Oro. (1620). Protocolo: 252, Registro Nro. 13. Folio: 645.

(49) ARC, Notarios, Lucero Alonso Beltran. (1630). Protocolo: 1, Registro Nro. 1. Folio: 585. 
dichapanaderiayen todo aquello que le mandare yocupare por el precio de sessenta pessos y cuando amase le a de dar de rracion tres panes y a rrescivido los dicho sessenta pessos para pagar sus deudas de que se dio por contento y entregado a su voluntad (31/06/1640).(150)

Las deudas contraídas por lo indígenas (probablemente por tributos) los impulsaron a incursionar en el campo laboral de la colonia. Al ser contratado Andrés Quispe pagó su deuda, pero tendría que trabajar un año.

En siguiente documento se denomina "obligación":

"SSePan quantos esta carta vieren como yo blas menacho mercader morador en esta ciudad del cuzco del piru a ysabel sisa yndia panadera muger legitima de pedro chuque la cantidad de sesenta y un pesos corrientes de a ocho rreales el pesso para primero del mes de agosto que viene deste presente año(29/03/1650)."(51)

10 años más tarde Ysabel Sisa (panadera), adquiere una deuda por el monto de 61 pesos, el prestamista es un mercader (caracterizado por relacionarse con compradores, proveedores, prestamistas y acreedores) ${ }^{\mathbf{( 5 2 )}}$ lo cual puede dar cuenta de la activa participación de Ysabel Sisa dentro de la estructura socio-económica colonial.

\section{Diferencias salariales entre mujeres y varones indígenas}

El presente estudio no se encargará de determinar los factores en cuanto a las brechas salariales entre varones y mujeres, concretamente, nos interesa visibilizar que las diferencias salariales entre hombres y mujeres indígenas presentan antecedentes coloniales específicamente en el caso del Cusco y del Virreinato peruano.

Cabe aclarar, que en el cuadro Nro. 11 se muestra los salarios monetarios percibidos por los indígenas de ambos géneros. Sin embargo, la remuneración laboral de los indígenas adicionalmente constaba de vestido, alimentación, vivienda y otros relacionados. El vestido de las mujeres indígenas (que conformaba parte de la remuneración percibida), representa en nuestra época de estudio una forma de resistencia a la nueva estructura colonial, pues se conserva gran parte de las formas y usos del vestido prehispánico. Sin embargo, fueron los varones indígenas (maestros y oficiales) quienes iniciaron adoptando la vestimenta de los invasores.

(50) ARC, Notarios, Alonso Calvo. (1639-1640). Protocolo: 44, Registro Nro. 7. Folio: s/f.

(51) ARC, Notarios, Lorenzo Messa Andueza. (1620). Protocolo: 177, Registro Nro. 10. Folio: 460.

(52) Mazzeo, C. A. (1994). El comercio libre en el Perú: las estrategias de un comerciante criollo, José Antonio de Lavalle y Cortés, Conde de Premio Real, 1777-1815. Univ. Católica Perú. Pág. 104. 
Las diferencias salariales son saltantes, las mujeres indígenas a pesar que incursionaron activamente en el mercado laboral, el valor de su trabajo (mano de obra) es inferior en comparación con los indígenas varones. Esta marcada diferencia representa el inicio de la construcción de la figura de la mujer peruana subordinada (y tal cual subsiste hasta hoy).

\section{CUADRO Nro. 11}

\begin{tabular}{|l|c|l|r|}
\hline \multicolumn{3}{|c|}{ SALARIO ANUAL MONETARIO DE LA POBLACIÓN INDÍGENA CUSQUEÑA (1600-1650) } \\
\hline \multicolumn{3}{|c|}{ Mujeres indígenas } & \multicolumn{2}{c|}{ Varones indígenas } \\
\hline Amas de leche: salario mínimo & 12 pesos & Arriero: salario mínimo & 30 pesos \\
\hline Amas de leche: salario máximo & 20 pesos & Arriero: salario máximo & 140 pesos \\
\hline Empleada doméstica: salario mínimo & 10 pesos & Yanacona: salario mínimo & 20 pesos \\
\hline Empleada doméstica: salario máximo & 50 pesos & Yanacona: salario máximo & 104 pesos \\
\hline Cocinera y lavandera: salario mínimo & 15 pesos & Yanacona arriero: salario mínimo & 26 pesos \\
\hline Cocinera y lavandera: salario máximo & 50 pesos & Yanacona arriero: salario máximo & 120 pesos \\
\hline Chicheras: salario mínimo & 20 pesos & Yanacona labrador: salario mínimo & 12 pesos \\
\hline Chicheras: salario máximo & 50 pesos & Yanacona labrador: salario máximo & 90 pesos \\
\hline
\end{tabular}

Fuente: ARC, Notarios, Alonso Calvo. Prot. 44-45, Domingo de Oro. Prot. 263, Francisco Hurtado. Prot. 119, Francisco Ruiz Negrete. Prot. 289, Joseph Calvo. Prot. 52, Joseph Navarro. Prot. 240, Juan Flores de Bastidas. Prot. 96, Lorenzo Messa Andueza. Prot. 177, Luis Diez de Morales. Prot. 65, y Martin Lopez de Paredes. Prot. 135. (Elaboración propia).

Finalmente, pese a los esfuerzos de las mujeres indígenas (subordinadas y no subordinadas) por integrarse y acomodarse al naciente mercado laboral, se puede apreciar que las oportunidades laborales y los salarios percibidos, fueron más ventajosos para los indígenas del género masculino.

\section{Conclusiones:}

1. La desestructuración colonial trajo como consecuencia una nueva situación socio-económica, ante esa situación, las familias indígenas, en especial las mujeres indígenas, responden activa y pasivamente. La respuesta de las mujeres indígenas, es una respuesta activa, puesto que incursionan a la nueva economía como subordinadas (del común) y como no subordinadas (de la élite y del común). Las mujeres subordinadas trabajan como amas de leche (nodrizas), cocineras, lavanderas, empleadas domésticas y chicheras, mientras que las no subordinadas son panaderas, carniceras y costureras, pero, principalmente tienen la capacidad de contratar los servicios laborales de otros indígenas. 
2. Las diferencias salariales son saltantes, la mano de obra las mujeres indígenas, a pesar de que se incorporaron activamente al mercado laboral, vale mucho menos; presenta claras condiciones de subordinación (condiciones totalmente diferentes) y se empieza a construir la figura de la mujer subordinada (intendentes coloniales), condición que subsiste hasta hoy adscrita a labores domésticas en el que todos sus trabajos son menospreciados. Hay una feminización de ciertos trabajos en la época colonial como es el caso de las chicheras (antes, los indígenas varones también se dedicaban a esta labor). La remuneración económica colonial no fue una economía monetarizada al $100 \%$. El salario de los indígenas fue monetario y no monetario -en donde el vestido, alimentación, y otros- formarían parte del salario de éstos.

3. Hay que destacar el rol de las mujeres indígenas pudientes económicamente en la Colonia, algunas de ellas son subsistentes de la nobleza indígena y se les puede conocer con el epíteto de doña, fueron las que contrataron mano de obra indígena. Otro grupo de ellas estará definido por las indígenas emprendedoras (del común), son el germen de las empresarias, son mujeres comerciantes que contratan mano de obra indígena.

4. Hace falta más investigaciones sobre la manera de cómo la nueva economía incorpora al sujeto indígena al nuevo mercado laboral y, sobre todo, conocer cómo las mujeres se incorporan y son absorbidas en este escenario colonial a la nueva economía, a partir de eso la construcción de la femineidad es una construcción colonial. Hace falta estudios para conocer cómo fue esa construcción colonial.

\section{Bibliografía}

\section{Fuentes manuscritas}

Archivo Regional del Cuzco (ARC): Notarios,

Alonso Calvo. Protocolos: 44-45

Antonio Salas. Protocolo: 293

Cristobal de Luzero. Protocolo: 166

Diego Gaitan. Protocolo: 112

Domingo de Oro. Protocolos: 252 y 263-264

Francisco Hurtado. Protocolo: 119

Francisco Ruiz Negrete. Protocolo: 289 
Joan de Olave. Protocolos: 243 y 249

Joseph Calvo. Protocolo: 52

Joseph Navarro. Protocolo: 240

Joseph Solorzano. Protocolo: 308

Juan Flores de Bastidas. Protocolo: 96

Lorenzo Messa Andueza. Protocolo: 177

Lucero Beltran Alonso. Protocolos: 1 y 7

Luis Diez de Morales. Protocolos: 65-66 y 78

Martin Lopez de Paredes. Protocolo: 135

\section{Fuentes publicadas}

BURKETT, E. (1976). La mujer durante la conquista y la primera época colonial. Estudios Andinos, 5(1), 4-25.

CARTER, W., \& Albó, X. (1988). La comunidad aymara: un mini-estado en conflicto. Raíces de América, 451-493.

CONTRERAS Y VALVERDE, V. D. (1982). Relación de la ciudad del Cuzco. Relaciones geográficas, 2.

DE TRAZEGNIES GRANDA, F. (1991). Paradojas de la Modernización: El Contrato de Enganche. THEMIS: Revista de Derecho, (20), 13-20.

ESQUIVEL Y NAVIA, D. (1980). Noticias cronológicas de la gran ciudad del Cuzco. Ed. F. Denegri Luna, Fundación Wiesse, Lima.

FLORES, A. (1993). Buscando un Inka, Consejo Nacional para la Cultura y las Artes, Ed. Grijalbo, México 1993.

GLAVE, L. M. (1989). Trajinantes: caminos indígenas en la sociedad colonial: siglos XVIXVII. Lima: Instituto de apoyo agrario.

GOBIERNO REGIONAL DEL CUSCO. (2005). Diccionario Quechua - Español Quechua. Segunda ed., Cusco - Perú.

KLARÉN, Peter F.; Nación y sociedad en la historia del Perú; Instituto de Estudios Peruanos; Lima 2004.

LEVI-STRAUSS, Claude. La Alfarera celosa. Barcelona, Buenos Aires, México: Ed. Paidos, 1986. p. 76.

LÓPEZ, S., Araníbar, C., Bonilla, H., \& Burga, M. (1982). De imperio a nacionalidades oprimidas: notas sobre el problema nacional indígena. Nueva historia general del Perú. 
MAZZEO, C. A. (1994). El comercio libre en el Perú: las estrategias de un comerciante criollo, José Antonio de Lavalle y Cortés, Conde de Premio Real, 1777-1815. Univ. Católica Perú.

NICOLINI, J. T., \& García, C. L. (1984). Una reseña critica de la dominación en el Perú virreinal (segunda parte). Histórica, 8(2).

NOEJOVICH CHERNOFF, H., Suárez, M., Glave, L. M., Salas, M., \& Salazar-Soler, C. (2009). Compendio de historia económica del Perú II: Economía del período colonial temprano. Lima.

ORMEÑO, T. V. (1997). Migración y trabajo femenino a principios del siglo XVII: el caso de las indias en Lima. Histórica, 21(1), 135-157.

ROSTWOROWSKI, M. (1988). La mujer en la época prehispánica. Lima: IEP.

VALDERRAMA, A. Y. (1995). Las "reducciones", uno de los instrumentos del etnocidio. Revista complutense de historia de América, (21), 241-264. 